Yasuhiko Takemoto • Yasuyuki Suzuki

Akiko Tamakoshi • Osamu Onodera · Shoji Tsuji

Takashi Hashimoto • Nobuyuki Shimozawa • Tadao Orii

Naomi Kondo

\title{
Epidemiology of X-linked adrenoleukodystrophy in Japan
}

Received: June 14, 2002 / Accepted: July 31, 2002

\begin{abstract}
To clarify the epidemiology of X-linked adrenoleukodystrophy (ALD) in Japan, we performed a questionnaire survey. Two hundred eighty-six patients, including 154 from internal medicine, 100 from pediatrics, 21 from psychiatry, and 11 from other hospitals, were reported to have ALD between 1990 and 1999. The data on 154 patients revealed the phenotypic distribution to be as follows: childhood cerebral form (29.9\%), adrenomyeloneuropathy $(25.3 \%)$, adult cerebral form $(21.4 \%)$, adolescent form $(9.1 \%)$, olivo-ponto-cerebellar form $(8.4 \%)$, presymptomatic form $(4.5 \%)$, and symptomatic female patient $(1.3 \%)$. The adult cerebral form and olivo-ponto-cerebellar form were more common in Japan than in North America and Europe. The incidence of X-linked ALD in Japan was estimated to be between 1:30000 and 1:50000 boys, similar to previous reports. About half of the patients with adrenomyeloneuropathy and the olivo-ponto-cerebellar phenotype developed cerebral involvement with a mean interval of 8.2 and 2.2 years after ALD onset, respectively. The family histories revealed that brothers and first cousins tended to show similar phenotypes, whereas nephews tended to develop symptoms earlier than uncles. These data
\end{abstract}

Y. Takemoto $(\triangle) \cdot N$. Shimozawa $\cdot$ T. Orii $\cdot$ N. Kondo

Department of Pediatrics

Gifu University School of Medicine, 40 Tsukasa-machi, Gifu

500-8705, Japan

Tel. +81-58-265-1241; Fax +81-58-265-9011

e-mail: ttakemoto@hkg.odn.ne.jp

Y. Suzuki

Medical Education Development Center, Gifu University School of Medicine, Gifu, Japan

A. Tamakoshi

Department of Preventive Medicine, Nagoya University School of

Medicine, Nagoya, Japan

O. Onodera $\cdot$ S. Tsuji

Department of Neurology, Brain Research Institute, Niigata

University, Niigata, Japan

T. Hashimoto

Shinshu University School of Medicine, Matsumoto, Japan will help in understanding the natural history of X-linked ALD.

Key words X-linked adrenoleukodystrophy - Epidemiology $\cdot$ Phenotype $\cdot$ Incidence $\cdot$ AMN $\cdot$ OPC $\cdot$ Adult cerebral form

\section{Introduction}

$\mathrm{X}$-linked adrenoleukodystrophy (ALD) is the most common peroxisomal disorder, characterized by demyelination of the central nervous system, adrenal dysfunction, and the accumulation of very long chain fatty acids (VLCFAs). The ALD protein is a member of the ATP-binding cassette protein superfamily, and is located in the peroxisomal membrane (Mosser et al. 1993). It is considered to function as a transporter of VLCFAs (Shinnoh et al. 1995). Patients with X-linked ALD usually manifest psychomotor deterioration and visual disturbance during school age, or gait disturbance and dementia in adulthood. Recently, several therapeutic trials, including monounsaturated fatty acid supplementation (Rizzo et al. 1989), bone marrow transplantation (Aubourg et al. 1990), and lovastatin (Singh et al. 1998) or 4-phenylbutyrate (Kemp et al. 1998) administration, have been investigated. Bone marrow transplantation was effective for children in the early stages of ALD (Shapiro et al. 2000; Suzuki et al. 2000). Several distinct phenotypes of X-linked ALD have been reported: childhood cerebral form, adrenomyeloneuropathy (AMN), adult cerebral form, and others (Moser et al. 2001), and the incidence of X-linked ALD is estimated to be between 1:20000 and 1:200 000 (Bezman and Moser 1998; van Geel et al. 1994; Heim et al. 1997; Ruiz et al. 1998; Kirk et al. 1998). However, most of the data were based on patients in the United States and Europe, and there are no epidemiological data on X-linked ALD in Japan.

We performed a nationwide epidemiological survey of X-linked ALD in Japan during the 1990s and compared the results with data from the 1980s. We clarified the incidence of X-linked ALD and its phenotypic distribution in Japan. 


\section{Materials and methods}

A nationwide survey of X-linked ALD in Japan between 1990 and 1999 was performed. Initially, questionnaires requesting the number of patients with X-linked ALD between 1990 and 1999 were sent to 4802 departments of internal medicine, neurology, pediatrics, and psychiatry in hospitals with more than 200 beds, and to 77 special hospitals, including children's hospitals and national sanatoriums. Questionnaires asking for precise data on each patient were then sent to the 161 departments and hospitals that replied positively.

\section{Results}

The recovery rate of the first questionnaire was $53.6 \%$, and 286 ALD patients were reported between 1990 and 1999: 154 patients from internal medicine and neurology, 100 from pediatrics, 21 from psychiatry, and 11 from special hospitals. Of those, 113 received medical care in these hospitals in 1999. The current number of ALD patients in Japan was speculated to be between 155 and 215, taking into account the recovery rate of the first questionnaire.

In the second survey, precise data on 154 patients from 144 families were reported from 109 departments. The diagnostic criterion of ALD was the accumulation of VLCFAs, and cases without VLCFA data were excluded. Because VLCFA analyses were performed in several institutions and commercial laboratories by different methods, mean values or normal ranges were not shown. Gene mutations were clarified in $13 \%$ of the patients (data not shown). The number of patients per total millions of population in each district of Japan was as follows: Hokkaido, 4 patients per 5.6 million; Tohoku, 17 per 9.8; Kanto, 31 per 40.4; Chubu, 44 per 21.6; Kinki 19 per 22.7; Chugoku 6 per 7.7; Shikoku 3 per 4.1; Kyushu and Okinawa, 23 per 14.8 .

The most prevalent phenotype was the childhood cerebral form, characterized by psychomotor regression between 2 and 10 years (mean age at onset: 7.1 years) (Table 1). Although the absolute number of patients with the childhood form increased during the 1990s compared with data from the 1980s, the relative frequency decreased. The combined frequency of the childhood and adolescent form of ALD was about $40 \%$ of total patients. AMN, a form with gait disturbance because of spinal cord involvement, was the second most common form. The absolute number and relative frequency of patients with AMN in the 1990s were higher than those in the 1980s. The adult cerebral form, characterized by dementia or psychological problems, was the third most common form and its incidence was higher in the 1990s than in the 1980s. The olivo-ponto-cerebellar form (OPC) (Ohno et al. 1984), characterized by gait disturbance and ataxia, composed $8.4 \%$ of total patients. The number of presymptomatic boys with no clinical manifestations and symptomatic girls was small, and no patient with isolated insufficiency of the adrenal gland (Addison's disease phenotype) was reported. Sixteen of 39 AMN patients (41\%) and 6 of 13 OPC patients (46\%) developed cerebral involvement. The mean intervals between the onset of the disorder and cerebral involvement in AMN and OPC were 8.2 years and 2.2 years, respectively. The final relative frequency of the adult cerebral form is calculated to be $35.7 \%$, which is higher than the childhood form.

The age at onset in each phenotype is shown in Fig. 1. The first peak consisted of the childhood form between the ages of 6 and 10 years. The second peak predominantly consisted of AMN and the adult cerebral form between the ages of 26 and 35 years. The average age of patients with AMN was slightly younger than that of patients with the adult form $(P<0.05)$. The mean interval between onset and diagnosis in the childhood form was shorter than that in other phenotypes (Table 1). Patients with AMN, including subjects who later developed cerebral involvement, had a longer survival period than did those with other phenotypes (Table 1).

The number of newly manifested patients was estimated to be about 20 per year in Japan, calculated from the 10 new patients reported every year and the $54 \%$ recovery rate of the second survey. Because the number of male babies declined between the 1950s and 1990s in Japan from 1.0 million to 0.6 million per year, the incidence of X-linked ALD was estimated to be between 1:30000 and 1:50000 boys.

Of 144 families, 69 had a history of inheritance. Fiftyeight female carriers from 36 families were documented. Thirty-nine families had at least two male patients, includ-

Table 1. Phenotypes of ALD in Japan

\begin{tabular}{lllllr}
\hline & $\begin{array}{l}\text { Number of } \\
\text { patients } \\
\text { Phenotype }\end{array}$ & $\begin{array}{l}\text { Mean age } \\
\text { at onset in years } \\
\text { (range) }\end{array}$ & $\begin{array}{l}\text { Interval between } \\
\text { onset and diagnosis } \\
\text { (years) }\end{array}$ & $\begin{array}{l}\text { Interval between } \\
\text { onset and death } \\
\text { (years) }\end{array}$ & $\begin{array}{l}\text { Number of } \\
\text { patients } \\
1980-1989(\%)\end{array}$ \\
\hline Childhood & $4690-1999(\%)$ & $7.1(2-10)$ & 0.9 & 7.5 & $32(54.2)$ \\
Adolescent & $14(9.1)$ & $14.7(11-19)$ & 1.6 & 12.4 & $7(13.1)$ \\
AMN & $39^{\mathrm{a}(25.3)}$ & $30.2(13-51)$ & 5.8 & 7.5 & 8.7 \\
Adult cerebral & $33(21.4)$ & $36.8(21-58)$ & 3.2 & & $8(13.6)$ \\
OPC & $13^{\mathrm{a}}(8.4)$ & $38.0(17-52)$ & 5.4 & & \\
Presymptomatic & $7(4.5)$ & & & $6.8)$ \\
Symptomatic girl & $2(1.3)$ & & & & \\
\hline
\end{tabular}

ALD, Adrenoleukodystrophy; AMN, adrenomyeloneuropathy; OPC, olivo-ponto-cerebellar form

${ }^{a}$ Sixteen AMN patients and six OPC patients later developed cerebral involvement 


\section{number of patients}

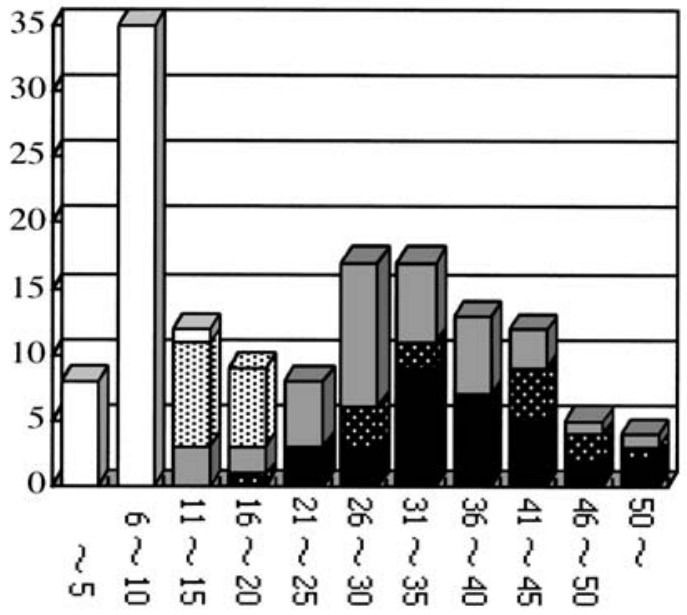

\begin{tabular}{l}
\hline$\square$ Childhood \\
国 Adolescent \\
$\square$ AMN \\
OPC \\
Adult cerebral \\
\hline
\end{tabular}

age (years)

Fig. 1. Age at onset in Japanese patients with adrenoleukodystrophy. $A M N$, Adrenomyeloneuropathy; $O P C$, olivo-ponto-cerebellar form

Table 2. Age at onset within the same family

\begin{tabular}{lll}
\hline & $\begin{array}{l}\text { Similar age } \\
\text { at onset }\end{array}$ & $\begin{array}{l}\text { Different age } \\
\text { at onset }\end{array}$ \\
\hline Brothers $(n=16)$ & $12^{\mathrm{a}}$ & 4 \\
First cousins $(n=10)$ & $10^{\mathrm{b}}$ & 0 \\
Uncles and nephews $(n=9)$ & 3 & $6^{\mathrm{c}}$
\end{tabular}

aMN and AMN: 4; childhood and childhood: 3; adult and AMN: 2; others: 3

${ }^{\mathrm{b}}$ Childhood and childhood: 7; adult and AMN: 2; adolescent and childhood: 1

${ }^{\mathrm{c}}$ AMN and childhood: 3 ; adult and childhood: 2; OPC and childhood: 1

ing suspected patients: 16 were brothers, 9 were uncles or nephews, and 10 were first cousins. Brothers and first cousins tended to show a similar age at onset, whereas uncles and nephews tended to show a different age at onset (Table 2).

Patient history did not clarify any significant relationship between the phenotypes and previous diseases. Brain disorders were identified in children (injury, 1; bleeding, 1; anoxia, 1) and adults (injury, 1; drowning, 1). Allergic disorders were more common in children (asthma, 7; dermatitis, 5; rhinitis, 1 ) than in adults (asthma, 1 ; rhinitis, 1 ); probably due to a general tendency at a younger age. Other complications in children were mental delay, 2; ventricular septal defect, 2; Down syndrome, 1; neurofibromatosis, 1; and insulin-dependent diabetes mellitus, 1 . Other complications in adults were diabetes mellitus, 3; cystic lung disease, 3; color blindness, 1; ulcerative colitis, 1; alcoholism, 1; IgA nephropathy, 1; hypertension, 1 ; cleft lip, 1 ; renal anomaly, 1 ; and hip dislocation, 1.

\section{Discussion}

The total number of patients in the 1990s increased to over twice those identified 10 years ago, suggesting that ALD may now be widely recognized by physicians in Japan, although another possibility may be the wide introduction of magnetic resonance imaging examinations and VLCFA analysis during the past 10 years. The distribution of phenotypes in the 1990s was also greatly different from that in the 1980s. The childhood form plus the adolescent form, which composed about two thirds of total patients in the 1980s, decreased to about $40 \%$ in the 1990 s, similar to data from the United States and Europe (Moser et al. 2001; Bezman and Moser 1998; van Geel et al. 1994; Ruiz et al. 1998). On the other hand, adult patients, including those with AMN, the adult cerebral form, and with OPC, increased to about $55 \%$ in the 1990s. Although the clinical course of pediatric patients is relatively uniform, the onset in adult patients is more insidious and varied, and it is difficult to diagnose adult patients at an early stage. In this report, we did not investigate the genotype-phenotype relationship, because no precise data on mutations were available. Previous reports could not elucidate the genotype-phenotype relationship (Moser et al. 2001).

The point of phenotype distribution on which our data and the previous reports differed most is that the adult cerebral form is more common in Japan (21.8\%) than in Western countries, where the adult cerebral form makes up only a few percent (Moser et al. 2001; van Geel et al. 1994), except for $16 \%$ in the Spanish population (Ruiz et al. 1998). Our study also clarified that about half of patients with AMN or OPC developed cerebral involvement. The relative frequency of the adult cerebral form is calculated to be about one third of total patients, which is higher than the childhood form. This study also clarified that OPC is frequent in Japan: most of the previous reports on OPC have been from Japan (Ohno et al. 1984; Moser et al. 2001).

The Addison's disease phenotype might be very rare or overlooked in Japan, although several patients manifested adrenal insufficiency as the first symptom, followed by neurological manifestations. In previous reports from Western countries, about $15 \%$ of total patients had the Addison's disease phenotype (Bezman and Moser 1998). From 3\% to $80 \%$ of idiopathic Addison's disease was caused by ALD (Kong and Jeffcoate 1994; Jorge et al. 1994; Ronghe et al. 2002). More attention should be paid to young patients with adrenal insufficiency. Symptomatic female carriers might be also underestimated in this survey.

The speculated incidence of ALD in Japan in this study, between 1:30000 and 1:50000 boys, is similar to North America and Europe. However, the incidence of ALD in Japan may further increase because (1) the number of patients with ALD greatly increased in the past two decades, (2) there are districts with a low incidence, and (3) the Addison's disease phenotype and symptomatic female carriers have seldom been diagnosed in Japan.

The interval between onset and diagnosis was long in Japan, even in the childhood form, as reported previously 
(van Geel et al. 1993). Bone marrow transplantation may be effective if it is carried out when a patient's performance IQ is greater than 80 (Shapiro et al. 2000). Early diagnosis will benefit patients and families in receiving effective therapies and adequate genetic counseling.

It is uncertain why brothers and first cousins tend to show a similar age at onset, whereas uncles and nephews tend to show a different age at onset. Although some biases might be present, such as insufficient data in an old family history, these data should be considered when taking a family history and during genetic counseling. It was also unclear whether cystic lung disease, which was a complication in three adult patients, was coincidental or not; however, it is an interesting finding and should be noted when taking the patient history.

These data will aid in understanding the natural history of X-linked ALD and will also provide information to evaluate future therapeutic trials for this fatal disorder.

Acknowledgments This study was supported by a Research Grant on Specific Diseases from the Ministry of Health, Labour and Welfare of Japan.

\section{References}

Aubourg P, Blanche S, Jambaque I, Rocchiccioli F, Kalifa G, NaudSaudreau C, Rolland MO, Debre M, Chaussain JL, Griscelli C, Fischer A, Bougneres PF (1990) Reversal of early neurologic and neuroradiologic manifestations of X-linked adrenoleukodystrophy by bone marrow transplantation. N Engl J Med 322:1860-1866

Bezman L, Moser HW (1998) Incidence of X-linked adrenoleukodystrophy and the relative frequency of its phenotypes. Am J Med Genet 76:415-419

Heim P, Claussen M, Hoffmann B, Conzelmann E, Gartner J, Harzer K, Hunneman DH, Kohler W, Kurlemann G, Kohlschutter A (1997) Leukodystrophy incidence in Germany. Am J Med Genet 71:475478

Jorge P, Quelhas D, Oliveira P, Pinto R, Nogueira A (1994) X-linked adrenoleukodystrophy in patients with idiopathic Addison disease. Eur J Pediatr 153:594-597

Kemp S, Wei HM, Lu JF, Braiterman LT, McGuinness MC, Moser AB, Watkins PA, Smith KD (1998) Gene redundancy and pharmacological gene therapy: implications for X-linked adrenoleukodystrophy. Nat Med 4:1261-1268
Kirk EP, Fletcher JM, Sharp P, Carey B, Poulos A (1998) X-linked adrenoleukodystrophy: the Australasian experience. Am J Med Genet 76:420-423

Kong MF, Jeffcoate W (1994) Eighty-six cases of Addison's disease. Clin Endocrinol 41:757-761

Moser HW, Smith KD, Watkins PA, Powers J, Moser AB (2001) X-linked adrenoleukodystrophy. In: Scriver CR, Beaudet AL, Sly WS, Valle D (eds) The metabolic and molecular bases of inherited disease, 8th edn, vol 2. McGraw-Hill, New York, pp 3257-3301

Mosser J, Douar AM, Sarde CO, Kioschis P, Feil R, Moser H, Poustka AM, Mandel JL, Aubourg P (1993) Putative X-linked adrenoleukodystrophy gene shares unexpected homology with $\mathrm{ABC}$ transporters. Nature 361:726-730

Ohno T, Tsuchida H, Fukuhara N, Yuasa T, Harayama H, Tsuji S, Miyatake T (1984) Adrenoleukodystrophy: a clinical variant presenting as olivopontocerebellar atrophy. J Neurol 231:167-169

Rizzo WB, Leshner RT, Odone A, Dammann AL, Craft DA, Jensen ME, Jennings SS, Davis S, Jaitly R, Sgro JA (1989) Dietary erucic acid therapy for X-linked adrenoleukodystrophy. Neurology 39:1415-1422

Ronghe MD, Barton J, Jardine PE, Crowne EC, Webster MH, Armitage M, Allen JT, Steward CG (2002) The importance of testing for adrenoleucodystrophy in males with idiopathic Addison's disease. Arch Dis Child 86:185-189

Ruiz M, Coll MJ, Pampols T, Giros M (1998) X-linked adrenoleukodystrophy: phenotype distribution and expression of ALDP in Spanish kindreds. Am J Med Genet 76:424-427

Shapiro E, Krivit W, Lockman L, Jambaque I, Peters C, Cowan M, Harris R, Blanche S, Bordigoni P, Loes D, Ziegler R, Crittenden M, Ris D, Berg B, Cox C, Moser H, Fischer A, Aubourg P (2000) Long-term effect of bone-marrow transplantation for childhoodonset cerebral X-linked adrenoleukodystrophy. Lancet 356:713718

Shinnoh N, Yamada T, Yoshimura T, Furuya H, Yoshida Y, Suzuki Y, Shimozawa N, Orii T, Kobayashi T (1995) Adrenoleukodystrophy: the restoration of peroxisomal beta-oxidation by transfection of normal cDNA. Biochem Biophys Res Commun 210:830-836

Singh I, Khan M, Key L, Pai S (1998) Lovastatin for X-linked adrenoleukodystrophy. N Engl J Med 339:702-703

Suzuki Y, Isogai K, Teramoto T, Tashita H, Shimozawa N, Nishimura M, Asano T, Oda M, Kamei A, Ishiguro H, Kato S, Ohashi T, Kobayashi H, Eto Y, Kondo N (2000) Bone marrow transplantation for the treatment of X-linked adrenoleukodystrophy. J Inherit Metab Dis 23:453-458

van Geel BM, Assies J, Haverkort EB, Barth PG, Wanders RJ, Schutgens RB, Keyser A, Zwetsloot CP (1993) Delay in diagnosis of X-linked adrenoleukodystrophy. Clin Neurol Neurosurg 95:115120

van Geel BM, Assies J, Weverling GJ, Barth PG (1994) Predominance of the adrenomyeloneuropathy phenotype of X-linked adrenoleukodystrophy in The Netherlands: a survey of 30 kindreds. Neurology 44:2343-2346 